\title{
The Role of Cabozantinib as a Therapeutic Option for Hepatocellular Carcinoma: Current Landscape and Future Challenges
}

This article was published in the following Dove Press journal: Journal of Hepatocellular Carcinoma

\author{
Antonio D'Alessio (D) ${ }^{1,2}$ \\ Maria Giuseppina Prete (DD ${ }^{1,2}$ \\ Antonella Cammarota $\left(\mathbb{D}^{1,2}\right.$ \\ Nicola Personeni $\mathbb{D}^{1,2}$ \\ Lorenza Rimassa (iD) ${ }^{1,2}$ \\ 'Department of Biomedical Sciences, \\ Humanitas University, Pieve Emanuele \\ (Milan), 20090, Italy; ${ }^{2}$ Medical Oncology \\ and Hematology Unit, Humanitas Cancer \\ Center, IRCCS Humanitas Research \\ Hospital, Rozzano (Milan), 20089, Italy
}

\begin{abstract}
The systemic treatment of advanced hepatocellular carcinoma (HCC) has significantly changed over the last years, with the introduction of two new standard-of-care firstline treatments (lenvatinib and the combination of atezolizumab and bevacizumab) and the success of several new agents in second line. In particular, after the approval of regorafenib, ramucirumab and cabozantinib, the landscape of second-line treatment has become notably complex, providing a serious challenge in clinical practice. In this review, we focus on cabozantinib, a multikinase inhibitor which was proven effective in improving overall and progression-free survival of patients previously treated with sorafenib in the randomized Phase III CELESTIAL trial. CELESTIAL is the only phase III study to have included patients in the third-line setting and cabozantinib efficacy was confirmed in several post hoc analyses, irrespective of alpha-fetoprotein levels, albumin-bilirubin score, age, and duration of previous sorafenib treatment. The safety profile of cabozantinib in the CELESTIAL trial was comparable with other multikinase inhibitors used for HCC and the most frequent grade $\geq 3$ adverse events were diarrhea, palmar-plantar erythrodysesthesia, fatigue, hypertension, and aspartate aminotransferase increase. Tolerability did not differ between younger and older patients and quality of life was significantly improved compared to placebo during the treatment. In this review, we also make a particular mention to the use of cabozantinib in populations which are normally excluded from clinical trials, such as older patients and Child-Pugh B patients. Finally, we present the new treatment strategies in which cabozantinib is being tested, most notably the combination of cabozantinib and atezolizumab in the first-line setting in the phase III COSMIC-312 trial and the use of cabozantinib after progression on immune-checkpoint inhibitors
\end{abstract}

Keywords: liver cancer, advanced, metastatic, second-line, third-line, special populations

\section{Introduction}

Liver cancer is the sixth most frequent cancer worldwide and the fourth most frequent cause of cancer-related death, causing 781,631 deaths globally every year. ${ }^{1}$ In particular, hepatocellular carcinoma (HCC) accounts for $90 \%$ of primary liver cancers and its treatment has seen a drastic evolution over the last years. The staging system of HCC follows the Barcelona Liver Cancer Clinic (BCLC) criteria. In case of advanced HCC, defined as BCLC C, or BCLC B deemed not amenable to further locoregional approaches, systemic treatment is needed. After ten years of sorafenib monopoly ${ }^{2,3}$ as the only approved drug, in the last years the landscape of HCC systemic treatments has become much more complex. As first-line treatment, lenvatinib was proven to be
Correspondence: Lorenza Rimassa; Nicola Personeni

Department of Biomedical Sciences, Humanitas University, Pieve Emanuele (Milan), 20090, Italy

Tel +3902 82244573; +390282244573

Fax +390282244590

Email lorenza.rimassa@hunimed.eu; nicola.personeni@hunimed.eu
Journal of Hepatocellular Carcinoma 2021:8 |77-19| 
non-inferior to sorafenib in terms of overall survival (OS) in the randomized phase III REFLECT study, ${ }^{4}$ while the combination of atezolizumab and bevacizumab performed better than sorafenib in terms of OS and progression-free survival (PFS) in the randomized phase III IMbrave150 study. ${ }^{5}$ In case of progression to sorafenib, several options are available. Three antiangiogenic drugs were proven effective in randomized phase III trials, thus obtaining the approval of both the European Medicines Agency (EMA) and the United States (US) Food and Drug Administration (FDA). Regorafenib and ramucirumab significantly improved OS compared to placebo in the $\mathrm{RESORCE}^{6}$ and $\mathrm{REACH}-2^{7}$ trials, respectively. Patients treated with regorafenib reached a median OS of 10.6 months vs 7.8 months in the placebo group, while median OS with ramucirumab was 8.5 months vs 7.3 months. Of note, regorafenib was tested in patients who had tolerated previous sorafenib treatment $(\geq 400 \mathrm{mg}$ daily for at least 20 of the 28 days before discontinuation), while the efficacy of ramucirumab was demonstrated only in the biomarker-selected population of patients with a baseline alpha-fetoprotein (AFP) of at least $400 \mathrm{ng} / \mathrm{mL}$. The third drug approved in the second-line setting is cabozantinib, which performed significantly better than placebo in terms of OS and PFS in the phase III CELESTIAL trial. ${ }^{8}$ In addition, the use of immune-checkpoint inhibitors (ICI) is possible in the US, where the FDA approved the use of nivolumab, pembrolizumab and the combination of nivolumab and ipilimumab after sorafenib on the basis of phase I/II trials. ${ }^{9-11}$ The presence of such a complex landscape in the second-line setting and the recent success of lenvatinib and immunotherapy as first-line treatments pose various challenges in clinical practice, and many questions, especially related to the best sequence of treatments, remain unsolved. In this review, we aim to summarize the actual evidence on the use of cabozantinib. We collected not only the main phase III data but also the corpus of abstracts and post hoc analyses, despite the potential biases and the limited statistical value of these latter, which are not intended to draw definite conclusions but are to be considered as hypothesis-generating. Indeed, we aim to help guide the decision-making process, with a particular focus on special populations, tolerability, and future perspectives.

\section{Efficacy of Cabozantinib}

Cabozantinib is an oral multikinase inhibitor (MKI), targeting vascular endothelial growth factor receptors (VEGFR1-3), the TAM kinase family (TYRO3, AXL and MER), KIT, RET, FLT3 and MET, which are crucial effectors in angiogenesis and tumorigenesis, commonly associated with the progression of $\mathrm{HCC}$ and with acquired resistance to sorafenib. The inhibition of MET and VEGFR2 signaling, induced by cabozantinib, leads to the blockade of essential oncogenic pathways, thus triggering apoptosis of endothelial and tumor cells and tumor regression in several preclinical models. ${ }^{12-16}$

\section{Efficacy Outcomes in the CELESTIAL Trial}

The role of cabozantinib in advanced $\mathrm{HCC}$ was investigated in the CELESTIAL trial, ${ }^{8}$ a multicenter, randomized, double-blind, placebo-controlled, phase III trial. The primary endpoint was OS and secondary endpoints were PFS and objective response rate (ORR) according to RECIST criteria version $1.1,{ }^{17}$ evaluated in the intention-to-treat (ITT) population. Eligible patients had a histologically confirmed diagnosis of advanced $\mathrm{HCC}$, disease progression on a maximum of two prior systemic regimens (at least one with sorafenib), preserved liver function (Child-Pugh class A) and Eastern Cooperative Oncology Group (ECOG) performance status (PS) scores of 0 or 1. Patients enrolled $(n=707)$ were stratified according to disease etiology (hepatitis B virus [HBV] with or without hepatitis $\mathrm{C}$ virus [HCV]; $\mathrm{HCV}$ without $\mathrm{HBV}$; or other etiologies), geographical region (Asia versus the rest of the world) and disease extension (macrovascular invasion [MVI], extrahepatic spread of disease [EHS] or both [yes or no]) and were randomized in a $2: 1$ ratio to receive cabozantinib, given orally at the dose of $60 \mathrm{mg}$ daily continuously, or a matching-placebo.

Of note, the stratification per geographical region is due to $\mathrm{HCC}$ epidemiology, since the pathogenesis is mainly HBVdriven in Asian countries, while $\mathrm{HCV}$ is the most frequent etiology in the rest of the world. In the ITT population cabozantinib significantly improved OS, providing a $24 \%$ reduction in the risk of death over placebo with a median OS of 10.2 months (95\% confidence interval [CI], 9.1-12.0) with cabozantinib versus 8.0 months (95\% CI, 6.8-9.4) with placebo (hazard ratio [HR] 0.76; 95\% CI, 0.63-0.92; $\mathrm{p}=0.005$ ). When used in the pure second-line population, who had received only prior sorafenib, the median OS was 11.3 months with cabozantinib in comparison to 7.2 months in the placebo arm (stratified HR 0.70, 95\% CI, 0.55-0.88). Moreover, a statistically significant benefit in all the secondary efficacy outcomes was achieved in the cabozantinib arm and these results are summarized in Tables 1 and 2 . 
Table I Summary of Survival Outcomes in the Intention-to-Treat Population and in Patient Subgroups

\begin{tabular}{|c|c|c|c|c|c|c|c|c|}
\hline \multirow{3}{*}{$\begin{array}{l}\text { Overall population } \\
(n=707)\end{array}$} & \multicolumn{2}{|c|}{ mOS Months $(95 \% \mathrm{Cl})$} & \multirow{3}{*}{$\begin{array}{c}\text { HR }(95 \% \mathrm{CI}) \\
0.76(0.63-0.92)\end{array}$} & \multirow{3}{*}{$\begin{array}{l}\mathbf{p} \text { value } \\
\mathrm{p}=0.005\end{array}$} & \multicolumn{2}{|c|}{ mPFS Months $(95 \% \mathrm{Cl})$} & \multirow{3}{*}{$\begin{array}{c}\text { HR }(95 \% \mathrm{Cl}) \\
0.44(0.36-0.52)\end{array}$} & \multirow{3}{*}{$\begin{array}{l}\text { p value } \\
p<0.00\end{array}$} \\
\hline & $\begin{array}{c}\text { Cabozantinib } \\
\qquad(\mathrm{n}=470)\end{array}$ & $\begin{array}{c}\text { Placebo } \\
(\mathrm{n}=237)\end{array}$ & & & $\begin{array}{c}\text { Cabozantinib } \\
(n=470)\end{array}$ & $\begin{array}{c}\text { Placebo } \\
(n=237)\end{array}$ & & \\
\hline & $10.2(9.1-12.0)$ & $8.0(6.8-9.4)$ & & & $5.2(4.0-5.5)$ & $1.9(1.9-1.9)$ & & \\
\hline \multicolumn{9}{|l|}{ Disease etiology } \\
\hline \multirow[t]{2}{*}{$\mathrm{HBV}(n=267)$} & $\begin{array}{c}\text { Cabozantinib } \\
\qquad(\mathrm{n}=178)\end{array}$ & $\begin{array}{l}\text { Placebo } \\
(n=89)\end{array}$ & & & $\begin{array}{c}\text { Cabozantinib } \\
\qquad(\mathrm{n}=178)\end{array}$ & $\begin{array}{c}\text { Placebo } \\
(\mathrm{n}=89)\end{array}$ & & \\
\hline & 9.7 & 6.1 & $0.69(0.5 \mathrm{I}-0.94)$ & NA & 4.4 & 1.8 & $0.31(0.23-0.42)$ & NA \\
\hline \multirow[t]{2}{*}{$\mathrm{HCV}(n=156)$} & $\begin{array}{c}\text { Cabozantinib } \\
\quad(n=105)\end{array}$ & $\begin{array}{c}\text { Placebo } \\
(n=5 I)\end{array}$ & & & $\begin{array}{c}\text { Cabozantinib } \\
\quad(n=105)\end{array}$ & $\begin{array}{c}\text { Placebo } \\
(n=5 I)\end{array}$ & & \\
\hline & 11.1 & 11.4 & I.II (0.7I-I.7I) & NA & 4.1 & 1.9 & $0.61(0.42-0.88)$ & NA \\
\hline \multirow[t]{2}{*}{ Other $(n=284)$} & $\begin{array}{c}\text { Cabozantinib } \\
\qquad(\mathrm{n}=187)\end{array}$ & $\begin{array}{c}\text { Placebo } \\
(\mathrm{n}=97)\end{array}$ & & & $\begin{array}{c}\text { Cabozantinib } \\
\qquad(\mathrm{n}=187)\end{array}$ & $\begin{array}{c}\text { Placebo } \\
(\mathrm{n}=97)\end{array}$ & & \\
\hline & 11.1 & 8.7 & $0.72(0.54-0.96)$ & NA & 5.5 & 2.0 & $0.48(0.36-0.63)$ & NA \\
\hline \multicolumn{9}{|l|}{ Geographical region } \\
\hline \multirow[t]{2}{*}{ Asia $(N=175)$} & $\begin{array}{c}\text { Cabozantinib } \\
(n=116)\end{array}$ & $\begin{array}{c}\text { Placebo } \\
(n=59)\end{array}$ & & & $\begin{array}{c}\text { Cabozantinib } \\
(n=1 \mid 6)\end{array}$ & $\begin{array}{c}\text { Placebo } \\
(n=59)\end{array}$ & & \\
\hline & 10.9 & 10.2 & $1.01(0.68-1.48)$ & NA & 5.4 & 1.8 & $0.46(0.32-0.67)$ & NA \\
\hline \multirow[t]{2}{*}{ Other regions $(n=532)$} & $\begin{array}{c}\text { Cabozantinib } \\
\qquad(\mathrm{n}=354)\end{array}$ & $\begin{array}{c}\text { Placebo } \\
(n=178)\end{array}$ & & & $\begin{array}{c}\text { Cabozantinib } \\
\quad(n=354)\end{array}$ & $\begin{array}{c}\text { Placebo } \\
(n=178)\end{array}$ & & \\
\hline & 10.2 & 7.8 & $0.71(0.57-0.88)$ & NA & 5.2 & 1.9 & $0.45(0.37-0.56)$ & NA \\
\hline \multicolumn{9}{|l|}{ Disease extension } \\
\hline \multirow[t]{2}{*}{$M V I(n=210)$} & $\begin{array}{c}\text { Cabozantinib } \\
\qquad(\mathrm{n}=129)\end{array}$ & $\begin{array}{l}\text { Placebo } \\
(n=8 I)\end{array}$ & & & $\begin{array}{c}\text { Cabozantinib } \\
\qquad(\mathrm{n}=129)\end{array}$ & $\begin{array}{c}\text { Placebo } \\
(n=8 I)\end{array}$ & & \\
\hline & 7.6 & 5.3 & $0.75(0.54-1.03)$ & NA & 3.7 & 1.8 & $0.42(0.31-0.58)$ & NA \\
\hline \multirow[t]{2}{*}{ EHS $(n=55 I)$} & $\begin{array}{c}\text { Cabozantinib } \\
\qquad(\mathrm{n}=369)\end{array}$ & $\begin{array}{c}\text { Placebo } \\
(n=182)\end{array}$ & & & $\begin{array}{c}\text { Cabozantinib } \\
\quad(n=369)\end{array}$ & $\begin{array}{c}\text { Placebo } \\
(n=182)\end{array}$ & & \\
\hline & 9.6 & 6.9 & $0.72(0.58-0.89)$ & NA & 5.0 & 1.9 & $0.46(0.37-0.56)$ & NA \\
\hline \multirow[t]{2}{*}{$\begin{array}{l}\text { MVI and/or EHS } \\
(n=598)\end{array}$} & $\begin{array}{l}\text { Cabozantinib } \\
\quad(n=398)\end{array}$ & $\begin{array}{c}\text { Placebo } \\
(n=200)\end{array}$ & & & $\begin{array}{c}\text { Cabozantinib } \\
\qquad(\mathrm{n}=398)\end{array}$ & $\begin{array}{c}\text { Placebo } \\
(\mathrm{n}=200)\end{array}$ & & \\
\hline & 9.5 & 7.3 & $0.73(0.60-0.90)$ & NA & 5.0 & 1.9 & $0.45(0.37-0.54)$ & NA \\
\hline \multirow[t]{2}{*}{ None $(n=109)$} & $\begin{array}{c}\text { Cabozantinib } \\
\qquad(\mathrm{n}=72)\end{array}$ & $\begin{array}{c}\text { Placebo } \\
(n=37)\end{array}$ & & & $\begin{array}{c}\text { Cabozantinib } \\
\qquad(\mathrm{n}=72)\end{array}$ & $\begin{array}{c}\text { Placebo } \\
(n=37)\end{array}$ & & \\
\hline & 14.0 & 14.7 & $0.99(0.59-1.65)$ & NA & 5.6 & 2.0 & $0.46(0.29-0.74)$ & NA \\
\hline
\end{tabular}

Note: Data from. ${ }^{8,18,20}$

Abbreviations: $\mathrm{mOS}$, median overall survival; $95 \% \mathrm{Cl}, 95 \%$ confidence interval; $\mathrm{HR}$, hazard ratio; $\mathrm{p}$, p value; mPFS, median progression-free survival; $\mathrm{HBV}$, hepatitis $\mathrm{B}$ virus; $\mathrm{HCV}$, hepatitis C virus; NA, not available; MVI, macrovascular invasion; EHS, extrahepatic spread.

Further Analyses of the CELESTIAL Trial Efficacy by Disease Etiology, Geographical Region and Disease Extension

As previously mentioned, patients enrolled in the CELESTIAL trial were stratified according to disease etiology, geographical region and disease extension. Subgroup analyses of OS and PFS were prespecified except those based on EHS or MVI as separate factors and on sorafenib as the only prior therapy (Table 1). An advantage in OS and PFS was observed in HBV-patients ${ }^{18}$ 
Table 2 Tumor Response in the Intention-to-Treat Population

\begin{tabular}{|c|c|c|}
\hline & $\begin{array}{c}\text { Cabozantinib } \\
\qquad(n=470)\end{array}$ & $\begin{array}{l}\text { Placebo } \\
(n=237)\end{array}$ \\
\hline \multirow[t]{2}{*}{ ORR $^{\mathrm{a}}, \%,(95 \% \mathrm{Cl})$} & $4 \%(2.0-6.0)$ & $<1 \%(0.0-2.0)$ \\
\hline & \multicolumn{2}{|c|}{$p=0.009$} \\
\hline \multicolumn{3}{|l|}{ Best overall response, \% } \\
\hline Complete response & 0 & 0 \\
\hline Partial response & $4 \%$ & $<1 \%$ \\
\hline Stable disease & $60 \%$ & $33 \%$ \\
\hline Progressive disease & $21 \%$ & $55 \%$ \\
\hline Not evaluable/missing & $15 \%$ & $11 \%$ \\
\hline
\end{tabular}

Notes: ${ }^{a}$ ORR was evaluated by the investigator per RECIST criteria version I.I. Data from. ${ }^{8}$

Abbreviations: ORR, objective response rate; $95 \% \mathrm{Cl}, 95 \%$ confidence interval; $p$, $P$ value.

(mOS 9.7 with cabozantinib versus 6.1 months with placebo, HR 0.69; 95\% CI 0.51-0.94; mPFS 4.4 with cabozantinib versus 1.8 months with placebo, HR $0.31 ; 95 \% \mathrm{CI}$ 0.23-0.42), even though HBV-related HCC is usually associated to worse prognostic features. ${ }^{19}$ Moreover, patients treated with cabozantinib achieved similar results in terms of OS regardless of geographical region (median OS 10.2 months in patients from non-Asian regions and 10.9 in patients from Asian regions). ${ }^{8}$ Concerning the disease extension, in comparison to the results observed in the ITT population, longer OS was achieved in patients without MVI and/or EHS, since their presence is commonly associated to worse prognosis. ${ }^{19}$ In detail, when neither MVI nor EHS were present, patients on cabozantinib achieved a median OS of 14.0 months and a median PFS of 5.6 months. Nevertheless, despite the shorter survivals, the magnitude of the survival benefit was even greater in patients presenting with MVI and/or EHS (9.5 months with cabozantinib versus 7.3 months with placebo, HR 0.73 ; 95\% CI, 0.60-0.90), who accounted for nearly $85 \%$ of the patients enrolled, and in those with either EHS (9.6 vs 6.9 , HR $0.72 ; 95 \%$ CI, 0.58-0.89) or MVI (7.6 vs 5.3 , HR $0.75 ; 95 \% \mathrm{CI}, 0.54-1.03$ ) as separate factors, even if this latter analysis was not preplanned. Moreover, cabozantinib provided a PFS advantage regardless of the disease extension. ${ }^{20}$

\section{Efficacy by Prior Treatments}

In a post hoc analysis of the CELESTIAL trial, ${ }^{21}$ the survival outcomes were evaluated according to the number $(0, \geq 1,1-2, \geq 3)$ of prior transarterial chemoembolization (TACE), resulting in longer OS and PFS in the cabozantinib arm compared to the placebo arm irrespective of the number of previous TACE. In detail, patients who had received at least one TACE treatment reached a median OS of 11.4 months with cabozantinib (versus 8.6 months with placebo) whereas patients without a prior TACE reached a median OS of 9.5 months with cabozantinib (versus 7.2 months with placebo) (Table 3).

Moreover, as highlighted in a recently published post hoc analysis, $^{22}$ cabozantinib used after sorafenib as a second-line option provided a survival benefit regardless of the duration of prior sorafenib treatment ( $<3$ months, 3 to 6 months or $\geq 6$ months). Of note, for patients who received sorafenib for $\geq 6$ months, median OS reached 29.9 months with cabozantinib versus 25.8 months with placebo, considering survival from the start of sorafenib. In addition, a longer prior treatment with sorafenib was associated with a longer treatment duration with cabozantinib and better PFS and ORR (Table 3).

\section{Efficacy by ALBI Grade and Other Baseline Factors}

In a further post hoc analysis of the CELESTIAL trial, ${ }^{23}$ the survival outcomes were evaluated according to the baseline albumin-bilirubin (ALBI) grade, which is a score based on serum albumin and total bilirubin with a range from 1 to 3 where the highest grade is associated to a worse prognosis. The results showed longer median OS (17.5 months with cabozantinib and 11.4 months with placebo, HR 0.63; 95\% CI, 0.46-0.86) and median PFS (6.5 months with cabozantinib and 1.9 months with placebo, HR 0.42; 95\% CI, 0.32-0.56) for patients with ALBI grade 1 than for patients with ALBI grade 2 (median OS 8.0 months with cabozantinib and 6.4 months with placebo, HR 0.84; 95\% CI, 0.66-1.06; median PFS 3.7 months with cabozantinib versus 1.9 months with placebo, HR 0.46; 95\% CI, 0.37-0.58) (Table 4), thus confirming the prognostic value of the ALBI score in HCC. ${ }^{24}$

Further baseline factors, including alkaline phosphatase, neutrophil-to-lymphocyte ratio, number of disease sites, and ECOG PS were shown to be potential prognostic factors for OS, but none of them was predictive of OS benefit with cabozantinib. $^{25}$

Efficacy by Baseline and On-Treatment Levels of AFP and Other Biomarkers

In line with other MKIs, such as sorafenib ${ }^{26}$ and regorafenib, ${ }^{27,28}$ and more recently with atezolizumabbevacizumab, ${ }^{29}$ the prognostic role of AFP levels was investigated in a post hoc analysis of the CELESTIAL trial. ${ }^{30}$ The 
Table 3 Summary of Survival Outcomes by Prior Treatments

\begin{tabular}{|c|c|c|c|c|c|c|}
\hline & \multicolumn{2}{|c|}{$\operatorname{mOS}(95 \% \mathrm{Cl})$} & HR $(95 \% \mathrm{Cl})$ & \multicolumn{2}{|c|}{ mPFS $(95 \% \mathrm{Cl})$} & HR (95\% Cl) \\
\hline \multicolumn{7}{|c|}{ According to prior TACE } \\
\hline \multirow[t]{2}{*}{$\begin{array}{l}\text { No prior TACE } \\
(n=393)\end{array}$} & $\begin{array}{l}\text { Cabozantinib } \\
\qquad(\mathrm{N}=267)\end{array}$ & $\begin{array}{l}\text { Placebo } \\
(N=126)\end{array}$ & \multirow[b]{2}{*}{$0.69(0.54-0.90)$} & $\begin{array}{l}\text { Cabozantinib } \\
\qquad(N=267)\end{array}$ & $\begin{array}{l}\text { Placebo } \\
(\mathrm{N}=126)\end{array}$ & \multirow[b]{2}{*}{$0.43(0.33-0.54)^{2}$} \\
\hline & 9.5 & 7.2 & & \multicolumn{2}{|c|}{ NA } & \\
\hline \multirow[t]{2}{*}{ Prior TACE $(n=3 \mid 4)$} & $\begin{array}{c}\text { Cabozantinib } \\
\qquad(N=203)\end{array}$ & $\begin{array}{l}\text { Placebo } \\
(N=|| I)\end{array}$ & \multirow[b]{2}{*}{$0.82(0.62-1.09)$} & $\begin{array}{c}\text { Cabozantinib } \\
\qquad(N=203)\end{array}$ & $\begin{array}{l}\text { Placebo } \\
(N=\mid I I)\end{array}$ & \multirow[b]{2}{*}{$0.50(0.38-0.64)^{2}$} \\
\hline & 11.4 & 8.6 & & \multicolumn{2}{|c|}{ NA } & \\
\hline \multicolumn{7}{|c|}{ According to prior sorafenib treatment duration ${ }^{b}$} \\
\hline$<3$ months $(n=136)$ & $\begin{array}{l}\text { Cabozantinib } \\
\qquad(\mathrm{N}=89)\end{array}$ & $\begin{array}{l}\text { Placebo } \\
(\mathrm{N}=47)\end{array}$ & & $\begin{array}{c}\text { Cabozantinib } \\
\qquad(\mathrm{N}=89)\end{array}$ & $\begin{array}{l}\text { Placebo } \\
(\mathrm{N}=47)\end{array}$ & \\
\hline $\begin{array}{l}\text { From the start of } \\
\text { cabozantinib }\end{array}$ & $8.9(7.40-12.50)$ & $6.9(4.90-9.20)$ & $0.72(0.47-1.10)$ & $3.8(3.50-5.60)$ & $\begin{array}{c}1.8 \\
(1.70-1.90)\end{array}$ & $0.35(0.23-0.52)$ \\
\hline $\begin{array}{l}\text { From the start of } \\
\text { sorafenib }\end{array}$ & $13.3(11.50-19.0)$ & $10.4(8.50-14.70)$ & NA & \multicolumn{2}{|c|}{ NA } & NA \\
\hline $\begin{array}{l}3 \text { to } 6 \text { months } \\
(n=|4|)\end{array}$ & $\begin{array}{l}\text { Cabozantinib } \\
\qquad(\mathrm{N}=98)\end{array}$ & $\begin{array}{l}\text { Placebo } \\
(\mathrm{N}=43)\end{array}$ & \multirow[b]{2}{*}{$0.65(0.43-1.00)$} & $\begin{array}{c}\text { Cabozantinib } \\
\qquad(\mathrm{N}=98)\end{array}$ & $\begin{array}{l}\text { Placebo } \\
(\mathrm{N}=43)\end{array}$ & \multirow[b]{2}{*}{$0.37(0.25-0.56)$} \\
\hline $\begin{array}{l}\text { From the start of } \\
\text { cabozantinib }\end{array}$ & II.5 (8.90-18.10) & $6.5(4.80-12.30)$ & & $5.4(3.70-7.40)$ & $\begin{array}{c}1.9 \\
(1.90-2.20)\end{array}$ & \\
\hline $\begin{array}{l}\text { From the start of } \\
\text { sorafenib }\end{array}$ & $21.2(15.60-26.10)$ & I4.I (I0.20-20.0) & NA & \multicolumn{2}{|c|}{ NA } & NA \\
\hline$\geq 6$ months $(n=217)$ & $\begin{array}{c}\text { Cabozantinib } \\
\qquad(N=143)\end{array}$ & $\begin{array}{c}\text { Placebo } \\
(N=74)\end{array}$ & \multirow[b]{2}{*}{$0.82(0.58-1.16)$} & $\begin{array}{c}\text { Cabozantinib } \\
\qquad(N=143)\end{array}$ & $\begin{array}{c}\text { Placebo } \\
(N=74)\end{array}$ & \multirow[b]{2}{*}{$0.48(0.35-0.67)$} \\
\hline $\begin{array}{l}\text { From the start of } \\
\text { cabozantinib }\end{array}$ & $12.3(9.50-18.0)$ & $9.2(6.30-11.60)$ & & $5.7(5.20-7.30)$ & $\begin{array}{c}1.9 \\
(1.90-2.70)\end{array}$ & \\
\hline $\begin{array}{l}\text { From the start of } \\
\text { sorafenib }\end{array}$ & $29.9(25.90-32.60)$ & $25.8(22.30-33.00)$ & NA & \multicolumn{2}{|c|}{ NA } & NA \\
\hline
\end{tabular}

Notes: ${ }^{a}$ Only HR are available for PFS by prior TACE; ' $\mathrm{D}$ ata evaluated in the per-protocol second-line population of CELESTIAL. Data from. ${ }^{21,22}$

Abbreviations: mOS, median overall survival; $95 \% \mathrm{Cl}, 95 \%$ confidence interval; HR, hazard ratio; mPFS, median progression-free survival; TACE, transarterial chemoembolization; NA, not available.

Table 4 Summary of Survival Outcomes by ALBI Grade

\begin{tabular}{|c|c|c|c|c|}
\hline \multirow[b]{2}{*}{ ALBI Grade I } & \multicolumn{2}{|c|}{ mOS Months $(95 \% \mathrm{Cl})$} & \multicolumn{2}{|c|}{ mPFS Months $(95 \% \mathrm{Cl})$} \\
\hline & Cabozantinib $(\mathrm{N}=186)$ & Placebo $(N=182)$ & Cabozantinib $(\mathrm{N}=186)$ & Placebo $(\mathrm{N}=182)$ \\
\hline & 17.5 & 11.4 & 6.5 & 1.9 \\
\hline & \multicolumn{2}{|c|}{ HR $0.63(0.46-0.86)$} & \multicolumn{2}{|c|}{ HR $0.42(0.32-0.56)$} \\
\hline \multirow[t]{3}{*}{ ALBI Grade 2} & Cabozantinib (N=282) & Placebo $(N=133)$ & Cabozantinib (N=282) & Placebo $(\mathrm{N}=133)$ \\
\hline & 8.0 & 6.4 & 3.7 & 1.9 \\
\hline & \multicolumn{2}{|c|}{ HR $0.84(0.66-1.06)$} & \multicolumn{2}{|c|}{ HR $0.46(0.37-0.58)$} \\
\hline
\end{tabular}

Note: Data from. ${ }^{23}$

Abbreviations: $\mathrm{mOS}$, median overall survival; $95 \% \mathrm{Cl}, 95 \%$ confidence interval; mPFS, median progression-free survival; ALBI grade, (Albumin-Bilirubin) grade; HR, hazard ratio. 
efficacy outcomes (OS, PFS, ORR per RECIST criteria version 1.1) of the CELESTIAL trial were evaluated according to the baseline AFP levels, with a cut-off of $400 \mathrm{ng} / \mathrm{mL}$, which has proven to have a prognostic role, ${ }^{7,31}$ and according to the kinetics of AFP. In particular, an AFP response is defined as an AFP reduction $\geq 20 \%$ from baseline during treatment, while an AFP control is defined as a minor reduction or no change from baseline at the first tumor assessment on week 8. In detail, patients on cabozantinib with baseline AFP levels $<400 \mathrm{ng} / \mathrm{mL}$ achieved a median OS of 13.9 months (versus 10.3 months with placebo; HR 0.81; 95\% CI, 0.62-1.04) and patients on cabozantinib with baseline AFP levels $\geq 400 \mathrm{ng} / \mathrm{mL}$ reached a median OS of 8.5 months (versus 5.2 months with placebo; HR 0.71; 95\% CI, 0.54-0.94). Additionally, longer PFS and notably higher ORR were achieved in patients with baseline AFP $<400 \mathrm{ng} / \mathrm{mL}$ than in the AFP $\geq 400 \mathrm{ng} / \mathrm{mL}$ subgroup. Given the low rate of AFP response in the placebo group (13\% versus $50 \%$ with cabozantinib), the efficacy outcomes were evaluated only in the cabozantinib subgroup. Patients showing an AFP response achieved a median OS of 16.1 months (versus 9.1 months in non-responders; HR 0.61; 95\% CI, 0.45-0.84), longer PFS and better ORR (7\% versus $3 \%$ in nonresponders), with a lower rate of progressive disease as best response in AFP responders (15\% versus 29\% in non- responders). These results corroborate the hypothesis that AFP kinetics could represent a useful biomarker of response also during cabozantinib treatment. A summary of the survival outcomes according to baseline AFP levels and AFP response is reported in Table 5.

Further circulating biomarkers, including cabozantinib targets, their ligands, and other plasma proteins, were tested at baseline and at week 4 during treatment, and their baseline levels and on-treatment changes were correlated with OS and PFS. HRs for OS and PFS favored cabozantinib over placebo regardless of baseline levels of all biomarkers analyzed. Overall, these analyses identified prognostic and pharmacodynamic biomarkers but none of them was predictive of OS or PFS benefit with cabozantinib. ${ }^{32}$

\section{Comparison with Other Second-Line Therapies}

As previously mentioned, in the second-line setting different therapeutic options are currently available based on phase III data, namely regorafenib, cabozantinib, and ramucirumab. However, the lack of direct comparisons and the differences in the enrolled populations make it difficult to compare their results. In this context, a matching-adjusted indirect comparison (MAIC) was performed to compare the results of the CELESTIAL and RESORCE trials, taking into account only

Table 5 Summary of Survival Outcomes by AFP Baseline Levels and AFP Response

\begin{tabular}{|c|c|c|c|c|}
\hline & \multicolumn{2}{|c|}{ mOS Months $(95 \% \mathrm{Cl})$} & \multicolumn{2}{|c|}{ mPFS Months $(95 \% \mathrm{Cl})$} \\
\hline \multicolumn{5}{|l|}{ AFP baseline levels } \\
\hline \multirow[t]{3}{*}{$<400 \mathrm{ng} / \mathrm{mL}(\mathrm{n}=4 \mid 4)$} & Cabozantinib $(N=278)$ & Placebo $(N=\mid 36)$ & Cabozantinib $(\mathrm{N}=278)$ & Placebo $(N=136)$ \\
\hline & 13.9 & 10.3 & 5.5 & 1.9 \\
\hline & \multicolumn{2}{|c|}{ HR $0.8 \mathrm{I}(0.62-\mathrm{I} .04)$} & \multicolumn{2}{|c|}{ HR $0.47(0.37-0.60)$} \\
\hline \multirow[t]{3}{*}{$\geq 400 \mathrm{ng} / \mathrm{mL}(\mathrm{n}=293)$} & Cabozantinib $(\mathrm{N}=192)$ & Placebo $(\mathrm{N}=|0|)$ & Cabozantinib $(\mathrm{N}=192)$ & Placebo $(\mathrm{N}=\mid 0 \mathrm{I})$ \\
\hline & 8.5 & 5.2 & 3.9 & 1.9 \\
\hline & \multicolumn{2}{|c|}{ HR 0.7I (0.54-0.94) } & \multicolumn{2}{|c|}{ HR $0.42(0.32-0.55)$} \\
\hline \multicolumn{5}{|l|}{ AFP response ${ }^{a}$} \\
\hline \multirow[t]{2}{*}{ Yes } & \multicolumn{2}{|c|}{ Cabozantinib $(N=1 \mid 7)$} & \multicolumn{2}{|c|}{ Cabozantinib $(N=1 \mid 7)$} \\
\hline & \multicolumn{2}{|c|}{16.1} & \multicolumn{2}{|c|}{7.3} \\
\hline \multirow[t]{3}{*}{ No } & \multicolumn{2}{|c|}{ Cabozantinib $(N=1 \mid 9)$} & \multicolumn{2}{|c|}{ Cabozantinib $(N=1 \mid 9)$} \\
\hline & \multicolumn{2}{|c|}{9.1} & \multicolumn{2}{|c|}{4.0} \\
\hline & \multicolumn{2}{|c|}{ HR $0.6 \mathrm{I}(0.45-0.84)$} & \multicolumn{2}{|c|}{ HR $0.55(0.4 \mathrm{I}-0.74)$} \\
\hline
\end{tabular}

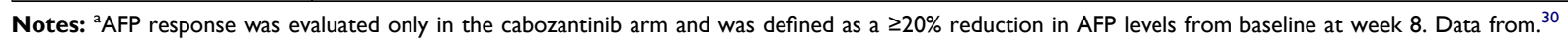
Abbreviations: $\mathrm{mOS}$, median overall survival; $95 \% \mathrm{Cl}, 95 \%$ confidence interval; mPFS, median progression-free survival; AFP, alpha-fetoprotein; HR, hazard ratio. 
the population who received cabozantinib as a second-line treatment. ${ }^{33}$ Although no statistically significant OS differences emerged (11.4 months for cabozantinib and 10.6 months for regorafenib, $\mathrm{p}=0.35$ ), a longer PFS was detected for cabozantinib (5.6 months for cabozantinib and 3.1 months for regorafenib, $\mathrm{p}=0.0005$ ). However, a potential confounding factor is represented by a different assessment schedule used in the two trials (every 8 weeks in the CELESTIAL trial and every 6 weeks for the first 8 cycles then every 12 weeks in the RESORCE trial). A recently presented MAIC was performed to compare the results of the CELESTIAL and REACH-2 trials, taking into consideration only the second-line population of the CELESTIAL trial with baseline AFP $\geq 400 \mathrm{ng} / \mathrm{mL}(\mathrm{n}=202) .{ }^{34}$ No statistically significant OS difference was observed (10.6 months with cabozantinib and 8.7 months with ramucirumab; $\mathrm{p}=0.104$ ) whereas a significantly longer PFS was achieved with cabozantinib (5.5 months versus 2.8 with ramucirumab; $\mathrm{p}=0.016$ ). Once again, the different schedule of assessments used in the two studies (every 8 weeks in the CELESTIAL trial and every 6 weeks for the first 6 months, then every 9 weeks for the REACH-2 study) might represent a potential confounding factor.

\section{Efficacy of Cabozantinib in the Third-Line Setting}

The population of the CELESTIAL trial ${ }^{8}$ could have received up to two lines of prior systemic treatments, and $27 \%(n=192)$ of the enrolled patients received cabozantinib as third-line treatment. As summarized in Table 6, these patients had shorter survivals (median OS 8.6 months in both arms, HR 0.90; 95\% CI, 0.63-1.29) than those who had received cabozantinib as a second-line option (11.3 with cabozantinib vs 7.2 months with placebo, HR $0.70 ; 95 \%$ CI $0.55-0.88$ ) but with a still preserved PFS advantage (3.7 months with cabozantinib versus 1.9 months with placebo, HR 0.40; 95\% CI, 0.32-$0.50)$. However, the trial was not powered to detect survival differences within these two strata. Nevertheless, even if in recent years new treatments were introduced in the first-line and second-line settings, cabozantinib still represents the only validated third-line therapeutic option. In particular, in the CELESTIAL trial, less than $5 \%$ of the patients received cabozantinib after a second-line treatment with ICI. However, despite the small numbers, a post hoc analysis showed that these patients had a benefit from cabozantinib similar to other third-line patients. ${ }^{35}$ Specifically, 14 and 3 patients receiving respectively cabozantinib and placebo in the third-line setting had received prior ICI as well as the required sorafenib. The median OS in the cabozantinib arm was 7.9 months and median PFS was 3.7 months, consistently with the results in the overall third-line subgroup.

\section{Tolerability Safety Findings in the CELESTIAL Trial} In the CELESTIAL trial, of the 707 randomized patients, all but three received the treatment and were included in the safety analysis. ${ }^{8}$ The median duration of treatment was 3.8 months in the cabozantinib group and 2.0 months in the placebo group. Dose reductions (from $60 \mathrm{mg}$ to $40 \mathrm{mg}$ to $20 \mathrm{mg}$ daily) were required by $62 \%$ of patients on cabozantinib and $13 \%$ of patients on placebo, and median administered daily dose was $35.8 \mathrm{mg}$ for cabozantinib and $58.9 \mathrm{mg}$ for placebo. The rate of treatment discontinuation because of adverse events (AEs) that were considered to be related to the trial regimen was $16 \%$ in the cabozantinib group and 3\% in the placebo group and the AEs leading to

Table 6 Summary of Survival Outcomes in Second- and Third-Line Population

\begin{tabular}{|c|c|c|c|c|}
\hline \multirow{4}{*}{ Second-line population $(n=509)$} & \multicolumn{2}{|c|}{ mOS Months $(95 \% \mathrm{Cl})$} & \multicolumn{2}{|c|}{ mPFS Months $(95 \% \mathrm{Cl})$} \\
\hline & Cabozantinib $(n=335)$ & Placebo $(n=174)$ & Cabozantinib $(n=335)$ & Placebo $(n=174)$ \\
\hline & 11.3 & 7.2 & 5.5 & 1.9 \\
\hline & \multicolumn{2}{|c|}{ HR $0.70(0.55-0.88)$} & \multicolumn{2}{|c|}{ HR $0.40(0.32-0.50)$} \\
\hline \multirow[t]{3}{*}{ Third-line population $(n=192)$} & Cabozantinib $(n=130)$ & Placebo $(n=62)$ & Cabozantinib $(n=130)$ & Placebo $(n=62)$ \\
\hline & 8.6 & 8.6 & 3.7 & 1.9 \\
\hline & \multicolumn{2}{|c|}{ HR $0.90(0.63-1.29)$} & \multicolumn{2}{|c|}{ HR $0.58(0.4 \mathrm{I}-0.83)$} \\
\hline
\end{tabular}

Note: Data from. ${ }^{8}$

Abbreviations: $\mathrm{mOS}$, median overall survival; $95 \% \mathrm{Cl}, 95 \%$ confidence interval; mPFS, median progression-free survival; HR, hazard ratio. 
treatment discontinuation in more than $1.0 \%$ of patients were palmar-plantar erythrodysesthesia (PPE), fatigue, decreased appetite, diarrhea and nausea. Ninety-nine percent of the patients treated with cabozantinib experienced at least one $\mathrm{AE}$ of any grade, compared to $92 \%$ of the patients in the placebo group, regardless of causality. High-grade AEs, defined as grade 3 or above according to Common Terminology Criteria for Adverse Events (CTCAE) version 4.0 , were reported by $68 \%$ of patients on cabozantinib and $32 \%$ of patients on placebo. Most common high-grade AEs were PPE (17\% of patients on cabozantinib vs $0 \%$ of patients on placebo), hypertension (16\% vs $2 \%$ ), increased aspartate aminotransferase (AST) levels ( $12 \%$ vs $7 \%)$, fatigue ( $10 \%$ vs $4 \%)$, and diarrhea ( $10 \%$ vs $2 \%)$. Dose reductions were mainly due to PPE $(22 \%)$, diarrhea $(10 \%)$, fatigue $(7 \%)$, hypertension $(7 \%)$ and AST increase $(6 \%)$. Fifty percent of patients on cabozantinib suffered from a serious AE versus 37\% of the placebo arm. Six patients treated with cabozantinib suffered from grade 5 treatment-related AEs (hepatic failure, bronchoesophageal fistula, portal-vein thrombosis, upper gastrointestinal hemorrhage, pulmonary embolism and hepatorenal syndrome), while 1 treatment-related death was reported in the placebo group (hepatic failure).

\section{Post Hoc Analyses}

The development of AEs is known to correlate with the efficacy of several MKIs used for advanced HCC. A survival improvement was shown for patients suffering from dermatologic AEs during the first 60 days of sorafenib treatment, $^{36}$ and confirmed for patients treated with regorafenib. ${ }^{37}$ More recently, a post hoc analysis of the REFLECT trial showed a positive association between AEs and OS for lenvatinib as well. ${ }^{38}$ Patients receiving cabozantinib who reported dermatological toxicity and grade $\geq 3$ hypertension were most likely to benefit from the treatment in terms of OS and PFS. ${ }^{39}$ For this reason, consistent with the experience acquired with sorafenib, ${ }^{40}$ it is of capital importance to learn how to manage AEs and how to improve the tolerability of cabozantinib in order not to discontinue the drug, since AEs may correlate with a better outcome. Describing in detail the management of AEs goes beyond the intent of this review, but it is important to underline the existence of many effective strategies aimed to prevent AEs and adequately treat them once they occur. ${ }^{41}$

A post hoc analysis extrapolated the data on quality of life (QoL) of patients enrolled in the CELESTIAL trial. ${ }^{42}$ Throughout the course of the treatment, QoL was evaluated with EQ-5D, which is a measure of health-related QoL, consisting of a descriptive system and the EuroQol-visual analogue scales. The analysis showed a significant although small health reduction after the first 50 days of the treatment, but this difference reduced over time and at 150 days patients receiving cabozantinib experienced a clinically and statistically increase in mean quality-adjusted life years (QALY), where every QALY is defined as one year of life spent in perfect health. Furthermore, restricting the analysis on patients receiving cabozantinib as a second-line treatment within the CELESTIAL study, a QTWiST analysis showed that these patients spent a significantly longer time without disease symptoms and high-grade toxicity in comparison with those receiving placebo. ${ }^{43}$ As previously mentioned, two MAICs focusing on second-line treatment compared cabozantinib with regorafenib ${ }^{33}$ and with ramucirumab, respectively. ${ }^{34}$ In the first MAIC, patients assigned to treatment arms in the CELESTIAL and RESORCE studies experienced similar rates of high-grade toxicity, in particular in terms of fatigue, hypertension, PPE and AST and bilirubin increase. The only difference was observed for high-grade diarrhea, which was significantly more frequent during cabozantinib treatment. ${ }^{33}$ Furthermore, the MAIC between the CELESTIAL and the REACH-2 trial highlighted a similar AE-related discontinuation rate in the two studies, with a slightly better tolerability of ramucirumab in terms of $\mathrm{G} \geq 3$ hypertension, fatigue and increased $\mathrm{AST}^{34}$

\section{Special Populations}

Despite the increasing number of therapeutic options, the management of advanced HCC can encounter severe limitations in daily practice, especially while taking care of patients with borderline clinical conditions. For these subgroups of patients, who were excluded or underrepresented in clinical trials, limited data are available. In particular, we report on the use of cabozantinib in two categories of patients: elderly patients and patients with impaired liver function (according to Child-Pugh score) (Table 7).

\section{Elderly Patients}

Although there is no consensus about the definition of elderly people, generally 65 years is considered the cutoff age according to the beginning of the retirement period in most Western countries. As a result of the different underlying etiologies, in Europe, America and Japan most $\mathrm{HCC}$ are diagnosed when patients are more than 60 years old, while in most of the African and Asian patients $\mathrm{HCC}$ diagnosis occurs between 30 and 60 years. With the 
Table 7 Summary of Survival Outcomes and Safety Data in Special Populations

\begin{tabular}{|c|c|c|c|c|c|c|c|}
\hline & & \multicolumn{2}{|c|}{$\begin{array}{l}\text { Overall Population }^{a} \\
\qquad(n=707)\end{array}$} & \multicolumn{2}{|c|}{$\begin{array}{l}\text { Elderly Patients }{ }^{b} \\
\qquad(n=343)\end{array}$} & \multicolumn{2}{|c|}{$\begin{array}{c}\text { Child-Pugh B at Week } 8^{c} \\
\qquad(n=73)\end{array}$} \\
\hline & & $\begin{array}{c}\text { Cabozantinib } \\
\qquad(n=470)\end{array}$ & $\begin{array}{l}\text { Placebo } \\
(n=237)\end{array}$ & $\begin{array}{c}\text { Cabozantinib } \\
\quad(n=230)\end{array}$ & $\begin{array}{l}\text { Placebo } \\
(n=|| 3)\end{array}$ & $\begin{array}{c}\text { Cabozantinib } \\
\qquad(n=5 I)\end{array}$ & $\begin{array}{c}\text { Placebo } \\
(n=22)\end{array}$ \\
\hline \multirow{2}{*}{$\begin{array}{l}\text { Survival } \\
\text { data }\end{array}$} & mOS & 10.2 & 8.0 & II.I & 8.3 & 8.5 & 3.8 \\
\hline & mPFS & 5.2 & 1.9 & 5.4 & 2.0 & 3.7 & 1.9 \\
\hline \multirow{2}{*}{$\begin{array}{l}\text { Adverse } \\
\text { Events }\end{array}$} & \%G3-G4 AEs & $68 \%$ & $37 \%$ & $68 \%$ & $33 \%$ & $71 \%$ & NA \\
\hline & $\begin{array}{c}\text { \% discontinuation } \\
\text { due to } A E s\end{array}$ & $16 \%$ & $3 \%$ & $22 \%$ & $4 \%$ & $18 \%$ & NA \\
\hline
\end{tabular}

Notes: ${ }^{\mathrm{a} D a t a}$ from; ${ }^{8}$ bata from; ${ }^{44}{ }^{\mathrm{c}}$ Data from. ${ }^{45}$

Abbreviations: mOS, median overall survival; mPFS, median progression-free survival; G, grade; AEs, adverse events, NA, not available.

notable exception of the Asia-Pacific trial, ${ }^{3}$ the median age of patients enrolled in clinical trials receiving second-line systemic treatment is 65 years. $^{2-6}$ In terms of efficacy endpoints, in the CELESTIAL trial the outcomes in elderly patients are comparable with the results in the overall population. ${ }^{44}$ Specifically, for patients $\geq 65$ years old, median OS was 11.1 months vs 8.3 months for cabozantinib and placebo, respectively (HR $0.74 ; 95 \%$ CI $0 .-$ 56-0.97), while median PFS was 5.4 months vs 2.0 months (HR 0.46; 95\% CI 0.35-0.59). Older patients discontinued the drug more often because of AEs (22\% discontinuation $\geq 65$ years vs $11 \%<65$ years) but interestingly the rate of dose reduction and the median administered daily dose did not differ. The most common high-grade AEs in both age groups were consistent with the safety profile reported in the overall population. Moreover, after progression on cabozantinib, $22 \%$ of patients with $\geq 65$ and $28 \%$ of patients $\leq 65$ years had access to further systemic treatments, showing that later lines can be safely administered regardless of age.

\section{Patients with Child-Pugh Class B Liver Cirrhosis}

Patients with advanced HCC and Child-Pugh class B liver cirrhosis represent a population with a worse prognosis. Due to the impaired liver function, they are excluded from clinical trials testing new therapeutic options for advanced HCC. Thus far, scarce data are available about the safety and efficacy of systemic treatment in this subgroup of patients. As other studies evaluating MKIs, the CELESTIAL trial allowed only Child-Pugh A patients. At baseline, the ratio of Child-Pugh scores of A6:A5 was similar ( $75 \%: 25 \%)$ for both arms. However, despite the inclusion criteria, 9 patients with Child-
Pugh class B were included in the trial: 7 in the cabozantinib arm versus 2 in the placebo arm. A post hoc analysis assessed patients whose liver function deteriorated from Child-Pugh class A to Child-Pugh class $\mathrm{B}$ by week 8 after randomization. ${ }^{45}$ This analysis showed a better median OS in patients with Child-Pugh class B on cabozantinib versus placebo (8.5 months vs 3.8 months), with a HR of 0.32 (95\% CI, 0.18-0.58). Similarly, the median PFS in the Child-Pugh B subgroup was longer in the cabozantinib arm compared to the placebo arm (3.7 months vs 1.9 months) with a HR of 0.44 (95\% CI, 0.25-0.76). Moreover, Child-Pugh B patients receiving cabozantinib had similar rates of dose reductions and treatment discontinuations than the overall population. Hence, cabozantinib seems to demonstrate a clinical benefit and a manageable safety profile also in patients with deteriorating liver function to Child-Pugh class B. Of note, nivolumab is the only available drug tested in patients with baseline Child-Pugh B class. In the CheckMate-040 the diseasecontrol rate and the median OS were 55.1\% and 7.6 months respectively in Child-Pugh B patients receiving nivolumab. ${ }^{46}$

\section{Cost-Effectiveness}

Since HCC is one of the most frequent cancers, it is important to consider the economic impact of a widespread use of a new drug once it enters the market. An extensive analysis of the cost-effectiveness of cabozantinib in the second-line setting was conducted by Liao et $\mathrm{al}^{47}$ considering three different healthcare systems (US, United Kingdom and China). The authors compared the cost-effectiveness of cabozantinib to best supportive care as in the CELESTIAL trial design, taking into account only direct medical costs, such as the price of the drug and the cost of grade 3-4 AEs management; as a measure of effectiveness, they used the gain in QALYs. In order to 
establish the cost-effectiveness of cabozantinib, they calculated the incremental cost-effectiveness ratio (ICER), which represents the incremental cost per QALY gained. The authors concluded that at the actual willingness-to-pay thresholds, cabozantinib is not cost-effective in any of the three healthcare systems. The highest cost was registered in the US, where they found an ICER of \$833 497 per QALY, while the lowest in China, with an ICER of $\$ 156$ 437 per QALY. To become cost-effective, the price of cabozantinib should be reduced at least by $80-85 \%$. However, this study has the limitation of not considering the indirect costs linked to cirrhosis complications, so that a possible clinical benefit from cabozantinib could have been underestimated. Another study, while identifying a modest gain of 0.16 QALYs for patients treated with cabozantinib after sorafenib discontinuation, confirms the lack of cost-effectiveness of the drug at the actual market price. $^{48}$ In 2015 the European Society of Medical Oncology (ESMO) created an innovative tool to evaluate the effectiveness of a new drug in terms of clinical benefit, the ESMO-Magnitude of Clinical Benefit Scale (ESMOMCBS). ${ }^{49}$ In its 1.1 version, this score assigns a number ranging from 1 (absence of clinical benefit) to 5 (substantial clinical benefit) for the drugs used in a non-curative setting, based on the overall evaluation of the median gain in terms of survival, the HR for OS and the improvement of QoL. ${ }^{50}$ Regarding its use in the second-line setting only, cabozantinib received a score of 3 , while in the same setting ramucirumab received a score of 1 and regorafenib a score of $4 .^{51}$

\section{Future Perspectives}

\section{Cabozantinib in Combination with $\mathrm{ICl}$}

Since 2007, antiangiogenic drugs have been the cornerstone of systemic therapies in HCC. However, in recent years the advent of immunotherapy in the HCC scenario is rapidly modifying the range of available systemic agents. Despite promising results in phase I/II studies, ${ }^{9,10}$ ICI monotherapy in first ${ }^{52}$ and second-line phase III trials ${ }^{53}$ demonstrated no statistically significant benefit in OS compared to sorafenib and placebo, respectively, confirming however the safety data observed in earlier phase trials. It is not possible to identify which patients will benefit the most from the treatment with ICI, since no biomarker has been validated and programmed death-ligand 1 (PD-L1) expression does not have any predictive value in HCC. Combining antiangiogenic agents with ICI has emerged as a potential approach to synergistically improve outcomes, and the positive results of the IMbrave150 study strongly support this strategy. ${ }^{5}$ Beyond the well-known broad spectrum of action, MKIs are also able to revert the immunosuppressive tumoral field, which is due to hypoxia and VEGF effects against immune cells, to an immunosupportive one. In this context, preclinical and clinical studies unveiled the immunomodulating properties of cabozantinib, showing that this drug is able to influence the innate and adaptative immune response in different types of tumor cells. $^{54-56}$ Of note, in addition to VEGFR2, cabozantinib targets other key pathways involved in immunosuppression (MET and TAM kinases: TYRO3, AXL, and MER) and it increases the expression of major histocompatibility complex class 1 antigen on tumor cells, which improves the sensitivity to $\mathrm{T}$ cell-mediated killing. The combination of anti-VEGF with ICI aims to reduce aberrant neoangiogenesis, thus promoting both drug delivery and CD8+ $\mathrm{T}$ cell infiltration in the tumor microenvironment. ${ }^{57} \mathrm{~A}$ recent study in an HCC murine model revealed that cabozantinib enhances antitumor activity both as monotherapy and in combination with ICI. At the systemic level, it increases the percentage of circulating $\mathrm{T}$ cells and CD8+T cells and it decreases the neutrophil-to-lymphocyte ratio. In addition, cabozantinib decreases the number of CD8+PD1+ lymphocytes and promotes the neutrophil infiltration into the tumor. The combination was significantly associated with upregulation of inflammation, innate and adaptive immunity pathways, both at systemic and at tumor level. ${ }^{58}$ Furthermore, in metastatic urothelial carcinoma patients, cabozantinib exhibited the ability to reduce circulating immunosuppressive regulatory $\mathrm{T}$ cells. ${ }^{55}$ In clinical trials, cabozantinib was tested in combination with ICI, showing promising antitumor activity and tolerability in patients with solid tumors, including pretreated HCC. ${ }^{59-62}$ Two phase I/II studies explored the combination of cabozantinib with ICI in advanced HCC patients with preserved liver function: CheckMate-040 (NCT01658878) and COSMIC021 (NCT03170960). The CheckMate-040 phase I/II study included a cohort of patients treated with cabozantinib (40 mg daily) plus nivolumab monotherapy or combined with ipilimumab. ${ }^{60}$ Recent results from this cohort reported an ORR of $29 \%$ in the cabozantinib-nivolumab-ipilimumab cohort and an ORR of $19 \%$ in the cabozantinib-nivolumab cohort; median PFS resulted in 6.8 months and 5.4 months, respectively while median OS was 21.5 months in the doublet arm, whereas it was not reached in the triplet arm. Moreover, cabozantinib in combination with 
atezolizumab was assessed in a multicenter Phase I study (COSMIC-021) in patients with multiple tumor types including HCC. After a promising benefit reported in patients with renal cell cancer with an acceptable safety profile in patients receiving cabozantinib at both planned doses (40 mg or $60 \mathrm{mg}$ daily) combined with atezolizumab (1200 mg every three weeks), ${ }^{62}$ results for HCC patients are eagerly awaited.

Thanks to these studies, a solid preclinical and clinical rationale supported the design of the ongoing COSMIC-312 study. This is a global, randomized, open-label phase III trial testing cabozantinib ( $40 \mathrm{mg}$ daily) combined with atezolizumab (1200 mg every three weeks) versus sorafenib (400 mg twice daily) and versus cabozantinib monotherapy (60 mg daily) in around 740 treatment-naïve patients with ChildPugh class A liver function and ECOG PS $0-1$. The primary endpoints are PFS according to RECIST version 1.1 assessed by a blinded independent radiology committee (BIRC) and OS for cabozantinib plus atezolizumab versus sorafenib. The secondary endpoint is PFS per RECIST version 1.1 by BIRC for cabozantinib monotherapy versus sorafenib. The protocol includes the evaluation of other efficacy endpoints, such as the ORR, time to progression and duration of response per RECIST version 1.1 by BIRC and the investigator. Furthermore, radiographic response is evaluated per modified RECIST as well. Additional analyses include the safety assessment, several biomarker analyses (eg, AFP) and the evaluation of QoL. ${ }^{63}$ A Phase II trial testing cabozantinib and pembrolizumab for first-line HCC treatment is ongoing (NCT04442581). Moreover, cabozantinib is currently tested in association with nivolumab as neoadjuvant treatment (NCT03299946) and to durvalumab in the second-line setting (NCT03539822) (Table 8).

\section{Expanding the Use of Cabozantinib Cabozantinib After ICI}

Thanks to the success of immunotherapy in the first-line setting and the ever-growing strategies of combination, the current landscape for HCC treatment is rapidly evolving. A wide number of treatment options are available for $\mathrm{HCC}$ patients, but it remains unknown which is the best treatment to adopt after ICI-based therapies, especially after the approval of atezolizumab and bevacizumab in the first-line setting. ${ }^{5}$ Regarding cabozantinib, retrospective data showed that it is active in patients with metastatic clear-cell renal cell carcinoma who had been previously treated with ICI. ${ }^{64}$ As previously mentioned, only retrospective data are available about the use of cabozantinib after ICI in HCC. These data, albeit limited, support its sequential use as a safe and promising strategy. ${ }^{35}$ Ongoing phase II clinical trials are prospectively assessing cabozantinib in HCC patients previously treated with ICI in first- or second-line (NCT04435977 IMMUNOCABO, NCT04316182 - ACTION).

\section{Cabozantinib and HIV}

Of all non-HIV-related cancers, HCC is one of the most studied malignancies occurring in people living with HIV (PLHIV), causing $40 \%$ of liver-related deaths in this population. ${ }^{65}$

Table 8 Cabozantinib in Combination with ICl: Ongoing Trials in HCC

\begin{tabular}{|l|c|c|c|c|c|c|}
\hline Trial Number & Trial Name & Phase & Combined ICI & Setting & Primary Outcomes & Secondary Outcomes \\
\hline NCT0375579I & COSMIC-312 & III & Atezolizumab & I line & PFS, OS & PFS \\
\hline NCT03170960 & COSMIC-02I & I/II & Atezolizumab & I line & MTD & ORR \\
\hline NCT0444258I & - & II & Pembrolizumab & I line & ORR & ORR, DCR, PFS, OS, AEs \\
\hline NCT01658878 & $\begin{array}{c}\text { CheckMate- } \\
040\end{array}$ & I/II & $\begin{array}{c}\text { Nivolumab/Nivolumab } \\
\text { +lpilimumab }\end{array}$ & I/Il line & AEs, ORR & $\begin{array}{c}\text { CRR, DCR, DOR, TTR, TTP, PFS, OS, } \\
\text { OSR }\end{array}$ \\
\hline NCT03539822 & CAMILLA & lb & Durvalumab & Il line & MTD & AEs, ORR, OBR, PFS, OS \\
\hline NCT04514484 & - & I & Nivolumab & Any line PLHIV & DLTs & Immune status, HIV viral loads, ORR \\
\hline NCT03299946 & CaboNivo & lb & Nivolumab & Neoadjuvant & $\begin{array}{c}\text { AEs, treatment } \\
\text { completion }\end{array}$ & $\begin{array}{c}\text { RO resection, CRR, MPR, ORR, OS, } \\
\text { DFS }\end{array}$ \\
\hline
\end{tabular}

Notes: active not recruiting, ${ }^{b}$ number of patients who complete preoperative treatment and proceed to surgery.

Abbreviations: $\mathrm{ICl}$, immune checkpoint inhibitor; HCC, hepatocellular carcinoma; PFS, progression-free survival; OS, overall survival; MTD, maximum tolerated dose; ORR, objective response rate; DCR, disease control rate; AEs, adverse events; CRR, complete response rate; DOR, duration of response; TTR, time to response; TTP, time to progression; OSR, overall survival rate; OBR, overall benefit rate; PLHIV, people living with HIV; DLTs, incidence of dose-limiting toxicities; HIV, human immunodeficiency virus; R0 resection, microscopically margin-negative resection; MPR, major pathologic response; DFS, disease-free survival. 
However, PLHIV are routinely excluded from prospective trials and no data are currently available about the use of systemic treatment in this population. It is known that PLHIV affected by HCC have a worse prognosis compared to the non-HIV counterpart, ${ }^{66}$ while assessing if they can safely receive systemic anticancer treatment is still an important unmet need. A phase I trial (NCT04514484) is currently investigating the use of cabozantinib and nivolumab in PLHIV with advanced cancers including HCC, with safety and feasibility as primary endpoints.

\section{Conclusion}

Cabozantinib is a standard of care for the treatment of advanced HCC in the second-line setting and the only approved option in third line, as CELESTIAL is the only phase III study to have included patients in the third-line setting. It is an effective and safe drug, and it appears to be feasibly employed even in more fragile patients who are normally excluded or underrepresented in clinical trials. Considering the actual complex landscape of second-line treatment of advanced HCC, the therapeutic choice should be tailored on each patient, based on clinical judgement, expected toxicity and regulatory issues. For example, the good tolerance of a previous MKI treatment could reassure the clinician on the safe use of cabozantinib, whereas a patient not benefitting from a first-line MKI could take a better advantage from an ICI, in countries where ICI are approved for previously treated patients. Furthermore, the presence of contraindicating factors, such as autoimmune diseases for immunotherapy or prothrombotic conditions for cabozantinib, should always be taken into consideration. Anyway, currently, no data are available to disentangle the therapeutic choice. ${ }^{67}$ In the near future, the use of cabozantinib could be expanded, depending on the results of ongoing studies exploring its role in first-line in combination with atezolizumab or in further lines of treatment following ICI discontinuation.

\section{Acknowledgments}

The authors are fully responsible for all content and editorial decisions. Ipsen and Exelixis provided courtesy review of the manuscript for scientific accuracy and fair balance. The authors were free to accept or decline the feedback.

\section{Disclosure}

NP received consulting fees from Amgen, Merck Serono, Servier; lectures fees from AbbVie, Gilead, Lilly, Sanofi; travel expenses from Amgen, ArQule; and institutional research funding from Basilea, Merck Serono, Servier. LR received consulting fees from Amgen, ArQule, AstraZeneca, Basilea, Bayer, BMS, Celgene, Eisai, Exelixis, Genenta, Hengrui, Incyte, Ipsen, IQVIA, Lilly, MSD, Nerviano Medical Sciences, Roche, Sanofi, Zymeworks; lecture fees from AbbVie, Amgen, Bayer, Eisai, Gilead, Incyte, Ipsen, Lilly, Merck Serono, Roche, Sanofi; travel expenses from Ipsen; and institutional research funding from Agios, ARMO BioSciences, AstraZeneca, BeiGene, Eisai, Exelixis, FibroGen, Incyte, Ipsen, Lilly, MSD, Nerviano Medical Sciences, Roche, Zymeworks.

The authors have no other relevant affiliations or financial involvement with any organization or entity with a financial interest in or financial conflict with the subject matter or materials discussed in the manuscript apart from those disclosed.

\section{References}

1. International Agency for Research on Cancer. The global cancer observatory; 2018. Available from: https://gco.iarc.fr/today/factsheets-cancers. Accessed November 26, 2020.

2. Llovet JM, Ricci S, Mazzaferro V, et al. Sorafenib in advanced hepatocellular carcinoma. $N$ Engl J Med. 2008;359(4):378-390. doi:10.1056/NEJMoa0708857

3. Cheng AL, Kang YK, Chen Z, et al. Efficacy and safety of sorafenib in patients in the Asia-Pacific region with advanced hepatocellular carcinoma: a phase III randomised, double-blind, placebo-controlled trial. Lancet Oncol. 2009;10(1):25-34. doi:10.1016/S1470-2045(08) 70285-7

4. Kudo M, Finn RS, Qin S, et al. Lenvatinib versus sorafenib in first-line treatment of patients with unresectable hepatocellular carcinoma: a randomised Phase 3 non-inferiority trial. Lancet. 2018;391 (10126):1163-1173. doi:10.1016/S0140-6736(18)30207-1

5. Finn RS, Qin S, Ikeda M, et al. Atezolizumab plus bevacizumab in unresectable hepatocellular carcinoma. $N$ Engl J Med. 2020;382 (20):1894-1905. doi:10.1056/NEJMoa1915745

6. Bruix J, Qin S, Merle P, et al. Regorafenib for patients with hepatocellular carcinoma who progressed on sorafenib treatment (RESORCE): a randomised, double-blind, placebo-controlled, phase 3 trial. Lancet. 2017;389(10064):56-66. doi:10.1016/S0140-6736(16)32453-9

7. Zhu AX, Kang YK, Yen CJ, et al. Ramucirumab after sorafenib in patients with advanced hepatocellular carcinoma and increased alpha-fetoprotein concentrations (REACH-2): a randomised, double-blind, placebo-controlled, phase 3 trial. Lancet Oncol. 2019;20(2):282-296. doi:10.1016/S1470-2045(18)30937-9

8. Abou-Alfa GK, Meyer T, Cheng AL, et al. Cabozantinib in patients with advanced and progressing hepatocellular carcinoma. $N$ Engl J Med. 2018;379(1):54-63. doi:10.1056/NEJMoa1717002

9. El-Khoueiry AB, Sangro B, Yau T, et al. Nivolumab in patients with advanced hepatocellular carcinoma (CheckMate 040): an open-label, non-comparative, Phase 1/2 dose escalation and expansion trial. Lancet. 2017;389(10088):2492-2502. doi:10.1016/S0140-6736(17)31046-2

10. Zhu AX, Finn RS, Edeline J, et al. Pembrolizumab in patients with advanced hepatocellular carcinoma previously treated with sorafenib (KEYNOTE-224): a non-randomised, open-label Phase 2 trial. Lancet Oncol. 2018;19(7):940-952. doi:10.1016/S1470-2045(18) 30351-6 
11. Yau T, Kang YK, Kim TY, et al. Efficacy and safety of nivolumab plus ipilimumab in patients with advanced hepatocellular carcinoma previously treated with sorafenib: the CheckMate 040 randomized clinical trial. JAMA Oncol. 2020;6(11):e204564. doi:10.1001/ jamaoncol.2020.4564

12. Yakes FM, Chen J, Tan J, et al. Cabozantinib (XL184), a novel MET and VEGFR2 inhibitor, simultaneously suppresses metastasis, angiogenesis, and tumor growth. Mol Cancer Ther. 2011;10 (12):2298-2308. doi:10.1158/1535-7163.MCT-11-0264

13. Rimassa L, Abbadessa G, Personeni N, et al. Tumor and circulating biomarkers in patients with second-line hepatocellular carcinoma from the randomized phase II study with tivantinib. Oncotarget 2016;7(45):72622-72633. doi:10.18632/oncotarget.11621

14. Xiang Q, Chen W, Ren M, et al. Cabozantinib suppresses tumor growth and metastasis in hepatocellular carcinoma by a dual blockade of VEGFR2 and MET. Clin Cancer Res. 2014;20 (11):2959-2970. doi:10.1158/1078-0432.CCR-13-2620

15. Firtina Karagonlar Z, Koc D, Iscan E, Erdal E, Atabey N. Elevated hepatocyte growth factor expression as an autocrine c-Met activation mechanism in acquired resistance to sorafenib in hepatocellular carcinoma cells. Cancer Sci. 2016;107(4):407-416. doi:10.1111/ cas. 12891

16. Trojan J. Cabozantinib for the treatment of advanced hepatocellular carcinoma: current data and future perspectives. Drugs. 2020;80 (12):1203-1210. doi:10.1007/s40265-020-01361-5

17. Eisenhauer EA, Therasse P, Bogaerts J, et al. New response evaluation criteria in solid tumours: revised RECIST guideline (version 1.1). Eur J Cancer. 2009;45(2):228-247. doi:10.1016/j. ejca.2008.10.026

18. Meyer T, Baron A, Gordan J, et al. O-012 outcomes in patients (pts) with hepatitis $\mathrm{B}$ virus (HBV) in the phase 3 CELESTIAL trial of cabozantinib (C) versus placebo $(\mathrm{P})$ in advanced hepatocellular carcinoma (HCC). ILCA Annual Conference - Book of abstracts; 2018:11-12.

19. Iavarone M, Cabibbo G, Biolato $M$, et al. Predictors of survival in patients with advanced hepatocellular carcinoma who permanently discontinued sorafenib. Hepatology. 2015;62(3):784-791. doi:10.1002/hep.27729

20. Blanc JF, Meyer T, Cheng A-L, et al. 703P assessment of disease burden in the phase III CELESTIAL trial of cabozantinib $(\mathrm{C})$ versus placebo (P) in advanced hepatocellular carcinoma (HCC). Ann Oncol. 2018;29:VIII237. doi:10.1093/annonc/mdy282.086

21. Yau T, Cheng A-L, Meyer T, et al. 704P outcomes by prior transarterial chemoembolization (TACE) in the phase III CELESTIAL trial of cabozantinib (C) versus placebo (P) in patients (pts) with advanced hepatocellular carcinoma (HCC). Ann Oncol. 2018;29:VIII237-238. doi:10.1093/annonc/mdy282.087

22. Kelley RK, Ryoo BY, Merle P, et al. Second-line cabozantinib after sorafenib treatment for advanced hepatocellular carcinoma: a subgroup analysis of the phase 3 CELESTIAL trial. ESMO Open. 2020;5(4):4. doi:10.1136/esmoopen-2020-000714

23. Chan S, Miksad R, Cicin I, et al. 127P outcomes based on albumin-bilirubin (ALBI) grade in the phase III CELESTIAL trial of cabozantinib versus placebo in patients with advanced hepatocellular carcinoma (HCC). Ann Oncol. 2019;30:IX45-IX46. doi:10.1093/annonc/mdz422.005

24. Pinato DJ, Sharma R, Allara E, et al. The ALBI grade provides objective hepatic reserve estimation across each BCLC stage of hepatocellular carcinoma. $J$ Hepatol. 2017;66(2):338-346. doi:10.1016/j.jhep.2016.09.008

25. Meyer T, Kelley RK, Mangeshkar M, Cheng A, El-Khoueiry AB, Abou-Alfa GK. 749P prognostic and predictive factors from the phase 3 CELESTIAL trial of cabozantinib (C) versus placebo (P) in previously treated advanced hepatocellular carcinoma (aHCC). Ann Oncol. 2019;30(suppl_5):v253-v324. doi:10.1093/annonc/ mdz247.075
26. Personeni N, Bozzarelli S, Pressiani T, et al. Usefulness of alpha-fetoprotein response in patients treated with sorafenib for advanced hepatocellular carcinoma. J Hepatol. 2012;57(1):101-107. doi:10.1016/j.jhep.2012.02.016

27. Bruix J, Reig M, Merle P, et al. 755P alpha-fetoprotein (AFP) response in patients with unresectable hepatocellular carcinoma (HCC) in the phase III RESORCE trial. Ann Oncol. 2019;30:v291v291. doi:10.1093/annonc/mdz247.081

28. Teufel M, Seidel H, Kochert K, et al. Biomarkers associated with response to regorafenib in patients with hepatocellular carcinoma. Gastroenterology. 2019;156(6):1731-1741. doi:10.1053/j. gastro.2019.01.261

29. Zhu AX, Dayyani F, Yen CJ et al. Alpha-fetoprotein (AFP) kinetics as a potential surrogate biomarker in patients (pts) with hepatocellular carcinoma (HCC) treated with atezolizumab (atezo) + bevacizumab (bev). ILCA Annual Conference - Book of Abstracts; 2020:12.

30. Kelley RK, Meyer T, Rimassa L, et al. Serum alpha-fetoprotein levels and clinical outcomes in the phase III CELESTIAL study of cabozantinib versus placebo in patients with advanced hepatocellular carcinoma. Clin Cancer Res. 2020;26(18):4795-4804. doi:10.1158/ 1078-0432.CCR-19-3884

31. Chau I, Park JO, Ryoo BY, et al. Alpha-fetoprotein kinetics in patients with hepatocellular carcinoma receiving ramucirumab or placebo: an analysis of the phase 3 REACH study. $\mathrm{Br} J$ Cancer. 2018;119(1):19-26. doi:10.1038/s41416-018-0103-0

32. Rimassa L, Kelley RK, Meyer T, et al. 678PD Outcomes based on plasma biomarkers for the phase 3 CELESTIAL trial of cabozantinib (C) versus placebo (P) in advanced hepatocellular carcinoma (aHCC). Ann Oncol. 2019;30(suppl_5):v253-v324. doi:10.1093/ annonc/mdz247.006

33. Kelley RK, Mollon P, Blanc JF, et al. Comparative efficacy of cabozantinib and regorafenib for advanced hepatocellular carcinoma. Adv Ther. 2020;37(6):2678-2695. doi:10.1007/s12325020-01378-y

34. Trojan J, Mollon P, Daniele B, et al. 1146 Comparative efficacy of cabozantinib and ramucirumab after sorafenib for patients with advanced hepatocellular carcinoma and AFP $\geq 400 \mathrm{ng} / \mathrm{mL}$. In: American Association for the Study of Liver Diseases (AASLD) the Liver Meeting Digital Experience. 2020.

35. Abou-Alfa G, Cheng A-L, Saletan S, Kelley K, El-Khoueiry A. PB02-04 clinical activity of cabozantinib in patients with advanced hepatocellular carcinoma previously treated with anti-VEGF and immuno-oncology therapy: subgroup analysis from the phase 3 CELESTIAL trial. Liver Cancer Summit - Abstract Book; 2020:234.

36. Reig M, Torres F, Rodriguez-Lope C, et al. Early dermatologic adverse events predict better outcome in HCC patients treated with sorafenib. $J$ Hepatol. 2014;61(2):318-324. doi:10.1016/j. jhep.2014.03.030

37. Bruix J, Merle P, Granito A, et al. Hand-foot skin reaction (HFSR) and overall survival (OS) in the phase 3 RESORCE trial of regorafenib for treatment of hepatocellular carcinoma (HCC) progressing on sorafenib. J Clin Oncol. 2018;36(suppl_4):412. doi:10.1200/ JCO.2018.36.4_suppl.412

38. Sung MW, Finn RS, Qin S, et al. Association between overall survival and adverse events with lenvatinib treatment in patients with hepatocellular carcinoma (REFLECT). J Clin Oncol. 2019;37 (suppl_4):317. doi:10.1200/JCO.2019.37.4_suppl.317

39. Abou-Alfa GK, Meyer T, Cheng A-L, et al. Association of adverse events (AEs) with efficacy outcomes for cabozantinib (C) in patients (pts) with advanced hepatocellular carcinoma (aHCC) in the phase III CELESTIAL trial. J Clin Oncol. 2019;37(suppl_15):4088. doi:10.1200/JCO.2019.37.15_suppl.4088

40. Scandurra G, Aiello RA, Ali M, et al. Appropriate management of cutaneous adverse events maximizes compliance with sorafenib treatment: a single-center experience. Future Oncol. 2012;8(5):609-615. doi:10.2217/fon. 12.35 
41. Rimassa L, Danesi R, Pressiani T, Merle P. Management of adverse events associated with tyrosine kinase inhibitors: improving outcomes for patients with hepatocellular carcinoma. Cancer Treat Rev. 2019;77:20-28. doi:10.1016/j.ctrv.2019.05.004

42. Abou-Alfa GK, Mollon P, Meyer T, et al. Quality-adjusted life years assessment using cabozantinib for patients with advanced hepatocellular carcinoma (aHCC) in the CELESTIAL trial. $J$ Clin Oncol. 2019;37(suppl_4):207. doi:10.1200/JCO.2019.37.4_suppl.207

43. Freemantle N, Abou-Alfa G, Cheng A, et al. Effect of second-line cabozantinib on health states for patients with advanced hepatocellular carcinoma (aHCC) after sorafenib: qTWiST analysis from the CELESTIAL study. Ann Oncol. 2019;30(suppl_5):v253-v324. doi:10.1093/annonc/mdz247.080

44. Rimassa L, Cicin I, Blanc J-F, et al. Outcomes based on age in the phase 3 CELESTIAL trial of cabozantinib $(\mathrm{C})$ versus placebo $(\mathrm{P})$ in patients (pts) with advanced hepatocellular carcinoma (HCC). J Clin Oncol. 2018;36(suppl_15):4090. doi:10.1200/JCO.2018.36.1 5_suppl.4090

45. El-Khoueiry A, Meyer T, Cheng A, et al. SO-9 outcomes for patients with advanced hepatocellular carcinoma and child-pugh B liver function in the phase 3 CELESTIAL study of cabozantinib vs placebo. Ann Oncol. 2020;31:S220. doi:10.1016/j.annonc.2020.04.024

46. Kudo M, Matilla A, Santoro A, et al. Checkmate-040: nivolumab (NIVO) in patients (pts) with advanced hepatocellular carcinoma (aHCC) and child-pugh B (CPB) status. J Clin Oncol. 2019;37 (suppl_4):327. doi:10.1200/JCO.2019.37.4_suppl.327

47. Liao W, Huang J, Hutton D, et al. Cost-effectiveness analysis of cabozantinib as second-line therapy in advanced hepatocellular carcinoma. Liver Int. 2019;39(12):2408-2416. doi:10.1111/liv.14257

48. Shlomai A, Leshno M, Goldstein DA. Cabozantinib for patients with advanced hepatocellular carcinoma: a cost-effectiveness analysis. Therap Adv Gastroenterol. 2019;12:1756284819878304. doi: $10.1177 / 1756284819878304$

49. Cherny NI, Sullivan R, Dafni U, et al. A standardised, generic, validated approach to stratify the magnitude of clinical benefit that can be anticipated from anti-cancer therapies: the European society for medical oncology magnitude of clinical benefit scale (ESMO-MCBS). Ann Oncol. 2015;26(8):1547-1573. doi:10.1093/ annonc/mdv249

50. Cherny NI, Dafni U, Bogaerts J, et al. ESMO-magnitude of clinical benefit scale version 1.1. Ann Oncol. 2017;28(10):2340-2366. doi:10.1093/annonc/mdx310

51. European Society of Medical Oncology. Magnitude of clinical benefit scale. Available from: https://www.esmo.org/guidelines/esmo-mcbs /esmo-mcbs-scorecards. Accessed November 26, 2020.

52. Yau T, Park JW, Finn RS, et al. LBA38PR CheckMate 459: a randomized, multi-center phase III study of nivolumab (NIVO) vs sorafenib (SOR) as first-line (1L) treatment in patients (pts) with advanced hepatocellular carcinoma (aHCC). Ann Oncol. 2019;30: v875-v875. doi:10.1093/annonc/mdz394.029

53. Finn RS, Ryoo BY, Merle P, et al. Pembrolizumab as second-line therapy in patients with advanced hepatocellular carcinoma in KEYNOTE-240: a randomized, double-blind, phase III trial. J Clin Oncol. 2020;38(3):193-202. doi:10.1200/JCO.19.01307

54. Kwilas AR, Ardiani A, Donahue RN, Aftab DT, Hodge JW. Dual effects of a targeted small-molecule inhibitor (cabozantinib) on immune-mediated killing of tumor cells and immune tumor microenvironment permissiveness when combined with a cancer vaccine. J Transl Med. 2014;12:294. doi:10.1186/s12967-014-0294-y
55. Apolo A, Tomita Y, Lee M, et al. 4501 Effect of cabozantinib on immunosuppressive subsets in metastatic urothelial carcinoma. J Clin Oncol. 2014;32(15s):4501. doi:10.1200/jco.2014.32.15_suppl.4501

56. Verzoni E, Ferro S, Procopio G, et al. 5737 Potent natural killer (NK) and myeloid blood cell remodeling by cabozantinib (Cabo) in pretreated metastatic renal cell carcinoma (mRCC) patients (pts). Ann Oncol. 2018;29(suppl_8):viii303-viii331. doi:10.1093/annonc/ mdy283.091

57. Pinter M, Jain RK, Duda DG. The current landscape of immune checkpoint blockade in hepatocellular carcinoma: a review. JAMA Oncol. 2020.

58. Esteban-Fabró R, Willoughby CE, Piqué-Gili M, et al. O-04 cabozantinib enhances the efficacy and immune activity of anti-PD1 therapy in a murine model of hepatocellular carcinoma. ILCA Annual conference - Book of Abstracts; 2020:6.

59. Nadal RM, Mortazavi A, Stein M, et al. Results of phase I plus expansion cohorts of cabozantinib (Cabo) plus nivolumab (Nivo) and CaboNivo plus ipilimumab (Ipi) in patients (pts) with metastatic urothelial carcinoma (mUC) and other genitourinary (GU) malignancies. J Clin Oncol. 2018;36(suppl_6):515. doi:10.1200/ JCO.2018.36.6_suppl.515

60. Yau T, Zagonel V, Santoro A, et al. Nivolumab (NIVO) + ipilimumab (IPI) + cabozantinib (CABO) combination therapy in patients (pts) with advanced hepatocellular carcinoma (aHCC): results from CheckMate 040. J Clin Oncol. 2020;38(suppl_4):478. doi:10.1200/ JCO.2020.38.4_suppl.478

61. Agarwal N, Vaishampayan U, Green M, et al. 5901 Phase 1b study (COSMIC-021) of cabozantinib in combination with atezolizumab: results of the dose escalation stage in patients (pts) with treatmentnaïve advanced renal cell carcinoma (RCC). Ann Oncol. 2018;29: viii303-viii331. doi:10.1093/annonc/mdy283.081

62. Pal S, Tsao C, Suarez C, et al. $702 \mathrm{O}$ Cabozantinib (C) in combination with atezolizumab (A) as first-line therapy for advanced clear cell renal cell carcinoma (ccRCC): results from the COSMIC-021 study. Ann Oncol. 2020;31(suppl_4):S550-S550. doi:10.1016/j. annonc.2020.08.774

63. Kelley RK, Oliver JW, Benzaghou F, Yau T, Cheng A-L, Rimassa L. Cabozantinib in combination with atezolizumab versus sorafenib in treatment-naive advanced hepatocellular carcinoma: COSMIC-312 Phase III study design. Future Oncol. 2020;16(21):1525-1536. doi:10.2217/fon-2020-0283

64. McGregor BA, Lalani AA, Xie W, et al. Activity of cabozantinib after immune checkpoint blockade in metastatic clear-cell renal cell carcinoma. Eur $J$ Cancer. 2020;135:203-210. doi:10.1016/j. ejca.2020.05.009

65. Rosenthal E, Roussillon C, Salmon-Ceron D, et al. Liver-related deaths in HIV-infected patients between 1995 and 2010 in France: the Mortavic 2010 study in collaboration with the Agence Nationale de Recherche sur le SIDA (ANRS) EN 20 Mortalite 2010 survey. HIV Med. 2015;16(4):230-239. doi:10.1111/hiv.12204

66. Pinato DJ, Allara E, Chen TY, et al. Influence of HIV infection on the natural history of hepatocellular carcinoma: results from a global multicohort study. J Clin Oncol. 2019;37(4):296-304. doi:10.1200/ JCO.18.00885

67. D’Angelo A, Sobhani N, Bagby S, Casadei-Gardini A, Roviello G. Cabozantinib as a second-line treatment option in hepatocellular carcinoma. Expert Rev Clin Pharmacol. 2020;13(6):623-629. doi:10.1080/17512433.2020.1767591 


\section{Publish your work in this journal}

The Journal of Hepatocellular Carcinoma is an international, peerreviewed, open access journal that offers a platform for the dissemination and study of clinical, translational and basic research findings in this rapidly developing field. Development in areas including, bu not limited to, epidemiology, vaccination, hepatitis therapy, pathology and molecular tumor classification and prognostication are all considered for publication. The manuscript management system is completely online and includes a very quick and fair peer-review system, which is all easy to use. Visit http://www.dovepress.com/ testimonials.php to read real quotes from published authors.

Submit your manuscript here: https://www.dovepress.com/journal-of-hepatocellular-carcinoma-journal 